\title{
Estimation of Diafenthiuron Residues in Cardamom (Elettaria cardamomum (L.) Maton) Using Normal Phase HPLC: Dissipation Pattern and Safe Waiting Period in Green and Cured Cardamom Capsules
}

\author{
Johnson Stanley, ${ }^{1}$ Subramanian Chandrasekaran, ${ }^{2}$ Gnanadhas Preetha, ${ }^{3}$ \\ Sasthakutty Kuttalam, ${ }^{2}$ and R. Sheeba Jasmine ${ }^{2}$ \\ ${ }^{1}$ Vivekananda Institute of Hill Agriculture, Almora 263601, India \\ ${ }^{2}$ Department of Agricultural Entomology, Tamil Nadu Agricultural University, Coimbatore 641003, India \\ ${ }^{3}$ Agricultural Research Station, Thirupathisaram, Tamil Nadu 629901, India
}

Correspondence should be addressed to Johnson Stanley; stanley_icar@rediffmail.com

Received 21 November 2013; Revised 9 January 2014; Accepted 13 January 2014; Published 24 February 2014

Academic Editor: Alberto Chisvert

Copyright (C) 2014 Johnson Stanley et al. This is an open access article distributed under the Creative Commons Attribution License, which permits unrestricted use, distribution, and reproduction in any medium, provided the original work is properly cited.

Diafenthiuron is an effective insecticide used for pest management in cardamom. Residues of diafenthiuron and its degradation/dissipation pattern in cardamom were determined to work out safe waiting period. Samples were collected after three sprays of diafenthiuron @ 400 and $800 \mathrm{~g}$ a.i ha ${ }^{-1}$ and the residues extracted in acetonitrile and quantified in normal phase HPLC in UV detector. Diafenthiuron was detected in $6.61 \pm 0.1 \mathrm{~min}$. The limits of detection (LOD) and limits of quantification (LOQ) were determined to be 0.01 and $0.05 \mu \mathrm{gmL}^{-1}$. The initial deposits were found to be 3.82 and $4.10 \mu \mathrm{g} \mathrm{g}^{-1}$ after sprays of diafenthiuron @ $400 \mathrm{~g}$ a.i ha ${ }^{-1}$ in the first and second experiments, respectively. Nearly cent percent of residues dissipated at 10 days after treatment in the recommended dose of diafenthiuron $400 \mathrm{~g}$ a.i ha ${ }^{-1}$ and the half life varied from 2.0 to 2.8 days with a waiting period of 5.5 to 6.7 days in green capsules of cardamom. The waiting period was 5.4 to 7.0 days in cured capsules of cardamom. With harvest being the focal point for enforcement of residue tolerances, the suggested waiting period of seven days is safe without the problem of pesticide residues in harvestable produce.

\section{Introduction}

The pesticide use pattern in the present day situations has led to pesticide residues in the harvestable produce, resistance build-up by pests, and eradication of nontargets which demands newer and safer pesticides with different modes of action. Diafenthiuron (1-tert-butyl-3-(2,6-diisopropyl thiourea)) is one such new insecticide, which is the only nonorganofluorine benzyl urea compound having novel insecticide/acaricide activity acting selectively on group of insects and mites [1] by inhibiting or enhancing biochemical sites such as respiration [2]. Diafenthiuron is reported to be effective against whiteflies and leaf hoppers in brinjal $[3,4]$, whiteflies, aphids and thrips in tomato [5$7]$, thrips and mitesin chilies and tea $[8,9]$, and all sucking pests in cotton [10, 11]. Diafenthiuron is effective against diamondback moth (DBM) [12,13], shoot and capsule borer, and thrips in cardamom [14] and it is gaining momentum now in cardamom plantations. Cardamom is an important spice crop grown all over the world and one of the important products fetching enormous foreign exchange. With the strict legislations enforced by the EPA, cardamom capsules with pesticide residues have a chance of being rejected by the hitherto importing countries, which in turn would have a major say in foreign revenues. Since diafenthiuron is effective against the pests of cardamom, knowledge on the residue in the economic produce, dissipation pattern, and waiting period are necessary for its proper use.

Diafenthiuron is a biologically inactive proinsecticide which needs transformation into active carbodiimide 


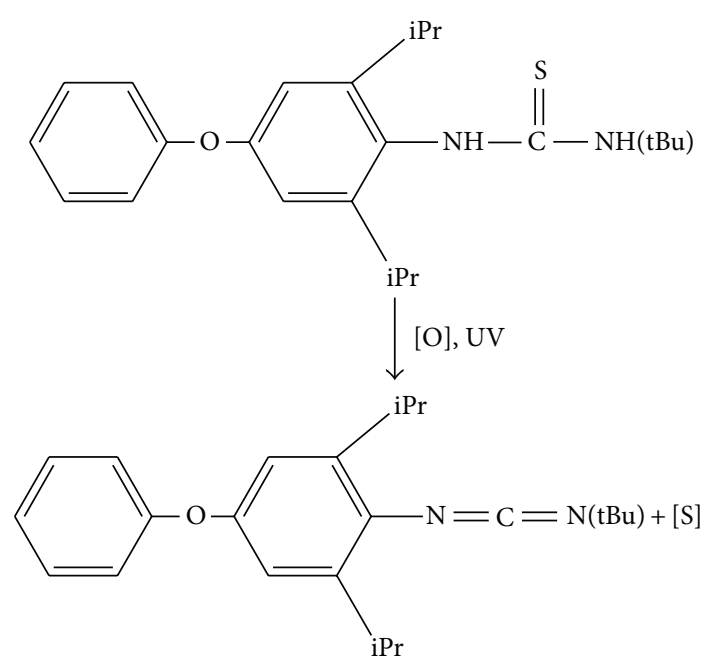

FIgURE 1: Activation of diafenthiuron into carbodiimide form [17].

derivative. In field conditions, it is photochemically transformed to 3-(2,6-di isopropyl-4-phenoxyphenyl)-1-tert-butyl carbodiimide (DFCD), which is considered to be the agent responsible for the biological activity $[15,16]$ (see Figure $1)$.

Direct photolysis by sunlight is the major degradation pathway of diafenthiuron [18] which is enhanced in humic acid water and aqueous acetone solutions [19]. Diafenthiuron behaves differently in plants as it exhibits strong translaminar and vapour activity. Diafenthiuron is reported to rapidly distribute into cuticular layer with a small portion persisting on the surface as dislodgeable residues. Keum et al. [19] extracted the dislodgeable residue of diafenthiuron by washing the leaves with Tween 80 , Dichloromethane (DCM), and then with methanol, partitioned with DCM and transferred into methanol to analyze in HPLC. In plant materials, diafenthiuron was analysed by extracting it in acetonitrile, partitioned with hexane and analysed in HPLC [19].

Diafenthiuron was reported to have faster degradation in Chinese cabbage which was fitted in first order kinetics [20]. Different rates of degradation of diafenthiuron were reported in cotton [15]. Diafenthiuron is not approved by Central Insecticide Board Registration Committee, India (CIB\&RC), for spray in brinjal in view of long waiting period of 10 days but approved for use in cardamom and subjected for fixing of tolerance limits [21]. Thus the present study is undertaken with the objective of detecting the harvest time residues and dissipation behaviour of diafenthiuron in fresh and cured cardamom capsules.

\section{Experimental}

2.1. Chemicals and Reagents. All the solvents were of analytical grade obtained from Merck, India. Diafenthiuron technical (93.5\% purity) obtained from M/s Syngenta India Limited and formulation (diafenthiuron 50 WP) obtained from Krishi Rasayan Exports Private Limited were used in the study. The reference standard of diafenthiuron (93.5\% purity) was made to 100 percent by transferring $1.07 \mathrm{~g}$ of the reference standard into a $100 \mathrm{~mL}$ volumetric flask which is then dissolved with distilled acetone: $\mathrm{n}$-hexane $(0.5: 9.5)$ and then volume was made up to $100 \mathrm{~mL}$. Then the flask was shaken well to get a homogenous solution of $1000 \mu \mathrm{g} \mathrm{mL}^{-1}$ (stock solution). This solution was diluted to respective concentrations for fortification studies. Formulation was used in field trials after dilution in tap water ( $\mathrm{pH} 7.2-7.5)$. For extraction of diafenthiuron, HPLC grade tertiary butyl methyl ether from J.T. Baker, USA, and anhydrous potassium carbonate from sdfine Chem Limited, Mumbai, were used.

2.2. Preparation of Standard Solutions. The solution for standard preparation, acetone: $\mathrm{n}$-hexane $(0.5: 9.5) \mathrm{v} / \mathrm{v}$, was prepared by adding $5 \mathrm{~mL}$ of acetone and $95 \mathrm{~mL}$ of $\mathrm{n}$-hexane. Likewise, mobile phase of HPLC, n-hexane, and tertiary butyl methyl ether $(65: 35) \mathrm{v} / \mathrm{v}$ was prepared by adding $65 \mathrm{~mL}$ of $\mathrm{n}$ hexane and $35 \mathrm{~mL}$ of tertiary butyl methyl ether. The cleanup solution of $4: 1 \mathrm{n}$-hexane and tertiary butyl methyl ether was prepared by adding $40 \mathrm{~mL}$ of $\mathrm{n}$-hexane and $10 \mathrm{~mL}$ of tertiary butyl methyl ether.

2.3. Field Experiments. Following good agricultural practices, field experiments were conducted at two different locations, namely, Bodimettu, Bodi, and the other Devarshola, Gudalur, India, during 2005-2006 using Randomised Block Design. Four cardamom clumps were taken for each replication and each treatment was replicated thrice. A control plot, where no pesticide was sprayed, was kept aside. Diafenthiuron 50 WP was sprayed @ $400 \mathrm{ga}^{\mathrm{a}} \mathrm{ha}^{-1}$ and $800 \mathrm{ga}^{\mathrm{i}} \mathrm{ha}^{-1}$ using Knapsack sprayer. Diafenthiuron is recommended for three sprays at 30 days interval in cardamom for cardamom shoot and capsule borer, Conogethes punctiferalis Gueneeand thrips, Sciothrips cardamomi Ramk. Hence, three sprays were given at 30 days interval when the crop is at the stage of flowering to capsule formation.

2.4. Sampling and Analytical Sample Preparation. Matured and uniform sized capsules were collected at random at the time of harvest and at $0(1 \mathrm{~h}), 1,3,7,15,21$, and 30 days after treatment with the help of forceps for determination of harvest time residues and dissipation after the third spray on cardamom. The interval between the last spray and the first harvest was 14 days in the first experiment and 17 days in the second experiment. From each plot, $150 \mathrm{~g}$ of green capsules was collected and, from this, a subsample of $25 \mathrm{~g}$ green capsules in duplicate was taken for fresh sample analysis and transferred immediately into the sample container with acetonitrile in the field itself. The remaining sample of $100 \mathrm{~g}$ was divided into two and was cured under conventional curing chamber with a maximum temperature of $60-65^{\circ} \mathrm{C}$ maintained for $24 \mathrm{~h}$ and used as cured samples for residue analysis. Thus a total of six samples were taken for analysis per treatment separately for green and cured capsules. The weights of the samples before and after curing were recorded from each plot in each sampling day to work out the residues on moisture free basis and curing loss. 


\subsection{Extraction}

2.5.1. Cardamom Capsules. Extraction mixture was prepared with $0.8 \%$ potassium carbonate and acetonitrile $(1: 4) \mathrm{v} / \mathrm{v}$ by adding $25 \mathrm{~mL}$ of potassium carbonate and $100 \mathrm{~mL}$ of acetonitrile. Twenty five grams of cardamom was macerated with $125 \mathrm{~mL}$ of extraction mixture by using homogenizer for $2 \mathrm{~min}$. The acetonitrile and potassium carbonate solution was filtered through Whatman number 42 filter paper in a Buchner funnel with mild vacuum suction. The process was repeated twice with $25 \mathrm{~mL}$ of acetonitrile. The combined extract was evaporated and volume reduced up to $10 \mathrm{~mL}$ by using rotary flash vacuum evaporator (below $40^{\circ} \mathrm{C}$ ).

2.5.2. Soil. The field soil samples collected at the time of collection of harvest time residues of capsules in both the experiments were air dried, grounded, and sieved through $100 \mathrm{~mm}$ mesh. $25 \mathrm{~g}$ of dry soil was placed into a $500 \mathrm{~mL}$ Erlenmeyer flask and $100 \mathrm{~mL}$ acetonitrile and $25 \mathrm{~mL}(0.8 \%)$ potassium carbonate solution was added. The flask was kept as such for 30 minutes with intermittent shakings. The contents were filtered by suction through Whatman number 42 filter paper in a Buchner funnel with mild vacuum. The soil cake was again mixed and stirred with $25 \mathrm{~mL}$ acetonitrile. The combined extract was reduced to $10 \mathrm{~mL}$ in rotary flask vacuum evaporator.

2.6. Cleanup Procedure. The concentrated extract $(10 \mathrm{~mL})$ was taken in a $250 \mathrm{~mL}$ separating funnel. To this $35 \mathrm{~mL}$ distilled water, two $\mathrm{mL}$ saturated sodium chloride, and five $\mathrm{mL}$ cleanup solution (as given in Section 2.2) were added, shaken well, and allowed to separate the two layers. Organic layer was collected and evaporated to dryness; the residue was dissolved in $10 \mathrm{~mL}$ of the HPLC grade $\mathrm{n}$-hexane : tertiary butyl methyl ether $(4: 1)$ mixture and analyzed using HPLC in UV detector.

\subsection{Chromatographic Conditions. The quantification} of residues was done using High Performance Liquid Chromatography (HPLC-Hitachi Model L 6200) equipped with normal phase column of Si-10 (Micropak) of $30 \mathrm{~cm}$ $\times 4 \mathrm{~mm}$ dimension. HPLC grade $\mathrm{n}$-hexane and tertiary butyl methyl ether 65:35 were used as mobile phase with a flow rate of $0.5 \mathrm{~mL} \mathrm{~min}^{-1}$ [22]. Injection was done with a rheodyne loop injector with a volume of $20 \mu \mathrm{L}$ and detected in L $4200 \mathrm{UV}$ detector at a wavelength of $256 \mathrm{~nm}$. The amount of diafenthiuron in the sample was calculated according to the equation based on the ratio of the peak areas of the standard and sample as follows:

$$
\text { Residues }=\frac{H_{s}}{H_{\text {std }}} \times \frac{W_{\text {std }}}{W_{s}} \times \frac{V_{s}}{A_{s j}},
$$

where $H_{s}$ is the peak height of the sample, $H_{\text {std }}$ is the peak height of the standard, $W_{\text {std }}$ is the weight of the standard injected in $\mathrm{ng}, W_{s}$ is the weight of the sample in $\mathrm{g}, V_{s}$ is the volume of the sample (final extract) in $\mathrm{mL}$, and $A_{\mathrm{sj}}$ is the Aliquot of the sample injected in $\mu \mathrm{L}$.
2.8. Method Validation and Recovery Studies. The parameters accuracy, precision, linearity, and limits of detection (LOD) and quantification (LOQ) were considered for method validation. For linearity test, different known concentrations of diafenthiuron $\left(0.25,0.5,1.0\right.$, and $\left.1.5 \mu \mathrm{g} \mathrm{mL}^{-1}\right)$ were prepared in distilled acetone: n-hexane $(0.5: 9.5) \mathrm{v} / \mathrm{v}$ by diluting the stock solution. Peak areas of each standard solution were measured after injecting in HPLC and a calibration curve plotted with concentration of standards versus area of the respective peaks obtained. The accuracy of the method was determined by recovery tests, using fresh cardamom capsule and soil sample ( $25 \mathrm{~g}$ ) taken from organically grown plantation. To work out the recovery percent of the analytical methodology, different known concentrations $(0.10$, $0.25,0.50$, and $1.0 \mu \mathrm{g} \mathrm{g}^{-1}$ ) of diafenthiuron were made by adding required quantity from $10 \mu \mathrm{g} \mathrm{g}^{-1}$ standard solution in cardamom capsule. Each concentration was taken in three replications. Samples were equilibrated for $1 \mathrm{~h}$ prior to extraction and subsequently taken through the extraction and cleanup procedures described above. The limit of detection (LOD, $\mu \mathrm{g} \mathrm{mL}^{-1}$ ) was determined as the lowest concentration giving a response of three times the baseline noise defined from the analysis of control (untreated) sample. The limit of quantification (LOQ, $\mu \mathrm{g} \mathrm{mL}^{-1}$ ) was determined as the lowest concentration of diafenthiuron giving a response of 10 times the baseline noise [23].

\section{Results and Discussion}

\subsection{Method Validation}

3.1.1. Specificity. Diafenthiuron was detected at $6.61 \mathrm{~min}$ (retention time) (Figure 2) through the above said procedures. Specificity was confirmed by injecting cardamom extract from cardamom not treated with diafenthiuron (control) and found no matrix peaks interfering with the retention time of diafenthiuron.

3.1.2. Linearity. Linearity test was made by plotting a standard graph/calibration curve with different standard concentrations $\left(0.25,0.5,1.0\right.$, and $\left.1.5 \mu \mathrm{g} \mathrm{mL}^{-1}\right)$ versus the respective area of the peaks obtained. The linear regression equation obtained was $y=33288 x+420.3$ with $R^{2} 0.9887$.

3.1.3. Detection and Quantification Limits. The limit of quantification was determined to be $0.05 \mu \mathrm{g} \mathrm{mL}^{-1}$. The limit of quantification of the analytical method in cardamom capsules was $0.05 \mu \mathrm{gg}^{-1}$ considering $25 \mathrm{~g}$ weight samples for extraction and $5 \mathrm{~mL}$ of sample extract. The limit of detection was determined to be $0.01 \mu \mathrm{g} \mathrm{mL}^{-1}$ at a level of approximately three times the background noise of control injection around the retention time of the peak of interest. The minimum detection limit (sensitivity) of the instrument was $0.25 \mu \mathrm{g} \mathrm{g}^{-1}$.

3.1.4. Precision, Repeatability, and Recovery Percentage. The mean recovery percentage was found to be $60.7,62.5,59.2$, and 59.3 in green capsules and 58.5, 59.3, 63.3, and 61.7 in cured capsules, respectively, for $0.10,0.25,0.50$, and $1.00 \mu \mathrm{gg}^{-1}$ in fortified levels. The standard deviations of 

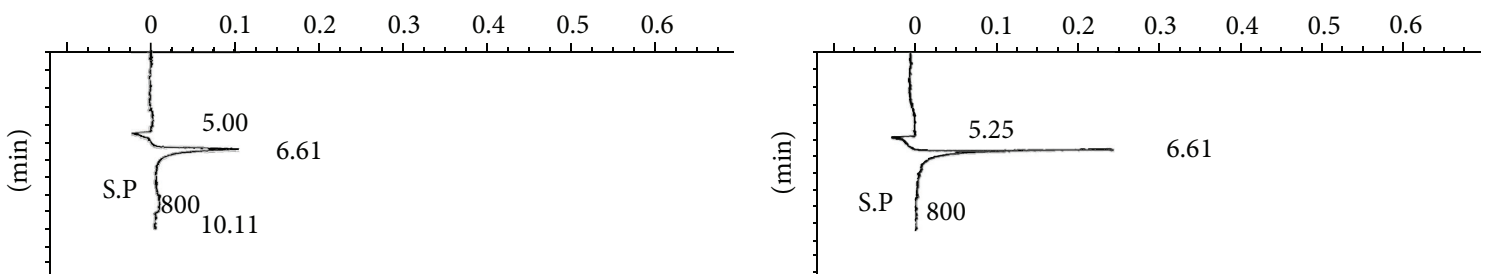

(a) $0.25 \mu \mathrm{g} \mathrm{mL}^{-1}$ of diafenthiuron standard

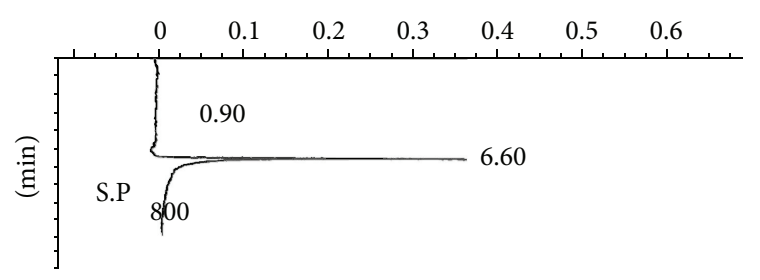

(c) $1.0 \mu \mathrm{g} \mathrm{mL}^{-1}$ of diafenthiuron standard

(b) $0.5 \mu \mathrm{g} \mathrm{mL}^{-1}$ of diafenthiuron standard

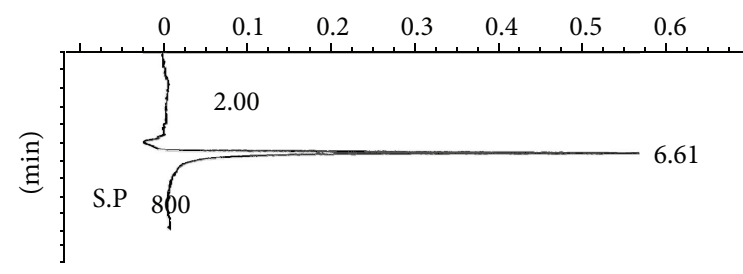

(d) $1.5 \mu \mathrm{g} \mathrm{mL}^{-1}$ of diafenthiuron standard

FIgURE 2: Standard chromatogram of diafenthiuron in HPLC.

recovery percentages for both green and cured capsules are well below $3 \%$ and thus the repeatability of the method is quite good. The mean recovery was 60.43 and 60.70 for green and cured capsules, respectively. The mean percent recovery of 60.6 was obtained in the present study on residue analysis of diafenthiuron, which is much lower than that of the expected recovery of more than 80 percent which is normally used for validation of residue protocols. It is presumed that the low recovery is due to the conversion of diafenthiuron into its metabolites, namely, N-[2,6-bis(1methylethyl)-4-phenoxyphenyl]- $\mathrm{N}^{\prime}$-(1,1-dimethylethyl)urea and N-[2,6-bis(1-methylethyl)-4-phenoxyphenyl]-N $\mathrm{N}^{\prime}-(1,1-$ dimethylethyl)carbodiimide [24], for which standards are not available. Thus the residue data obtained in the present study is only for the parent compound and hence weightage was given by multiplying the residues obtained with the recovery factor, 1.65 , to get the actual quantum of residue.

3.2. Harvest Time Residues in Cardamom Capsules. The residues of diafenthiuron in harvested capsules of cardamom both green and cured were below detectable limit at the time of first harvest after third spray. Residues of diafenthiuron in the soil samples on 14 and 17 days after application of diafenthiuron on cardamom, that is, at the time of harvest, were found below detectable limit (BDL).

3.3. Residues in Green Capsules of Cardamom, Half Life, and Waiting Period. The initial deposit on green capsules in diafenthiuron@ @ $400 \mathrm{ga} \mathrm{i} \mathrm{ha}^{-1}$ was 3.82 and $4.10 \mu \mathrm{gg}^{-1}$ in first and second field trials, respectively. The deposit was as high as 6.61 to $7.32 \mu \mathrm{gg}^{-1}$ at the higher dose of diafenthiuron ( $800 \mathrm{ga}_{\text {a }} \mathrm{ha}^{-1}$ ) (Tables 1 and 2 ). The residues dissipated to below detectable level (BDL) at 15 DAT in both the concentrations evaluated in two seasons. The extent of reduction in diafenthiuron residues at one DAT was 14.39 to 20.68 percent in diafenthiuron $400 \mathrm{~g}$.i ha ${ }^{-1}$. The half life values varied from 1.95 to 2.82 days for diafenthiuron @ $400 \mathrm{ga}^{\mathrm{i} h \mathrm{ha}^{-1}}$ and 3.42 to 3.61 days for $800 \mathrm{ga.i} \mathrm{ha}^{-1}$. The maximum residue level (MRL) value for diafenthiuron on cardamom is not available. Maximum Residue Limits (MRL) for diafenthiuron was fixed by Australian Pesticides and Veterinary Management Authority on other commodities, namely, cotton seed $\left(0.2 \mathrm{mg} \mathrm{g}^{-1}\right)$, peanut $\left(0.1 \mathrm{mg} \mathrm{g}^{-1}\right)$ and egg, meat, milk, and poultry $\left(0.02 \mathrm{mg} \mathrm{g}^{-1}\right)$ [25]. Japanese Food Chemical Research Foundation has suggested an MRL value of $0.3 \mu \mathrm{g} \mathrm{g}^{-1}$ for cabbage whereas $20 \mu \mathrm{g} \mathrm{g}^{-1}$ for tea [25]. Since the suggested MRL is of very wide range from $0.3 \mu \mathrm{gg}^{-1}$ to $20 \mu \mathrm{g} \mathrm{g}^{-1}$, the tentative MRL value of $0.5 \mu \mathrm{g} \mathrm{g}^{-1}$ for bell pepper used by Syngenta India Ltd was used for arriving waiting periods in cardamom in the present study. The waiting period worked out was 5.50 to 6.69 days for diafenthiuron @ $400 \mathrm{~g}$ a.i ha ${ }^{-1}$ and 11.33 to 11.40 days at $800 \mathrm{~g} \mathrm{a.i} \mathrm{ha}^{-1}$.

3.4. Residues in Cured Capsules of Cardamom, Half Life, and Waiting Period. The extent of dissipation of residues at one DAT was 22.33 to 24.19 and 19.07 to 21.07 percent in diafenthiuron @ $400 \mathrm{~g} \mathrm{a} . \mathrm{i} \mathrm{ha}^{-1}$ and $800 \mathrm{~g} . \mathrm{i} \mathrm{ha}{ }^{-1}$, respectively. The percent dissipation was more than 95 percent in diafenthiuron@ $400 \mathrm{~g} \mathrm{a.i} \mathrm{ha}{ }^{-1}$ at 10 DAT and the residues dissipated to BDL in 15 DAT. The half life was 1.78 days for diafenthiuron @ $400 \mathrm{ga}^{\mathrm{iha}}{ }^{-1}$ in both the trials and 1.59 to 3.02 for diafenthiuron@800ga.i ha ${ }^{-1}$. The waiting period worked out was 5.39 to 7.01 days for diafenthiuron @ $400 \mathrm{~g} \mathrm{a.i} \mathrm{ha}^{-1}$. The correlation coefficients $(r)$ of the calibration curves derived for dissipation of diafenthiuron in cured capsules are above 0.9 , which shows best fit (Tables 1 and 2).

3.5. Residues of Diafenthiuron Estimated in Moisture Free Basis. The initial deposit of diafenthiuron residues worked out on moisture free basis was 13.84 and $14.83 \mu \mathrm{gg}^{-1}$ in diafenthiuron@400 ga.i ha ${ }^{-1} ; 23.99$ and $25.71 \mu \mathrm{gg}^{-1}$ in diafenthiuron@800ga.i ha ${ }^{-1}$ in the first and second field trials, respectively. The residues detected in cured capsules were slightly high when compared to green capsules. But low level of quinalphos residues was reported earlier in cured capsules than green capsules [26]. Though there will be loss 


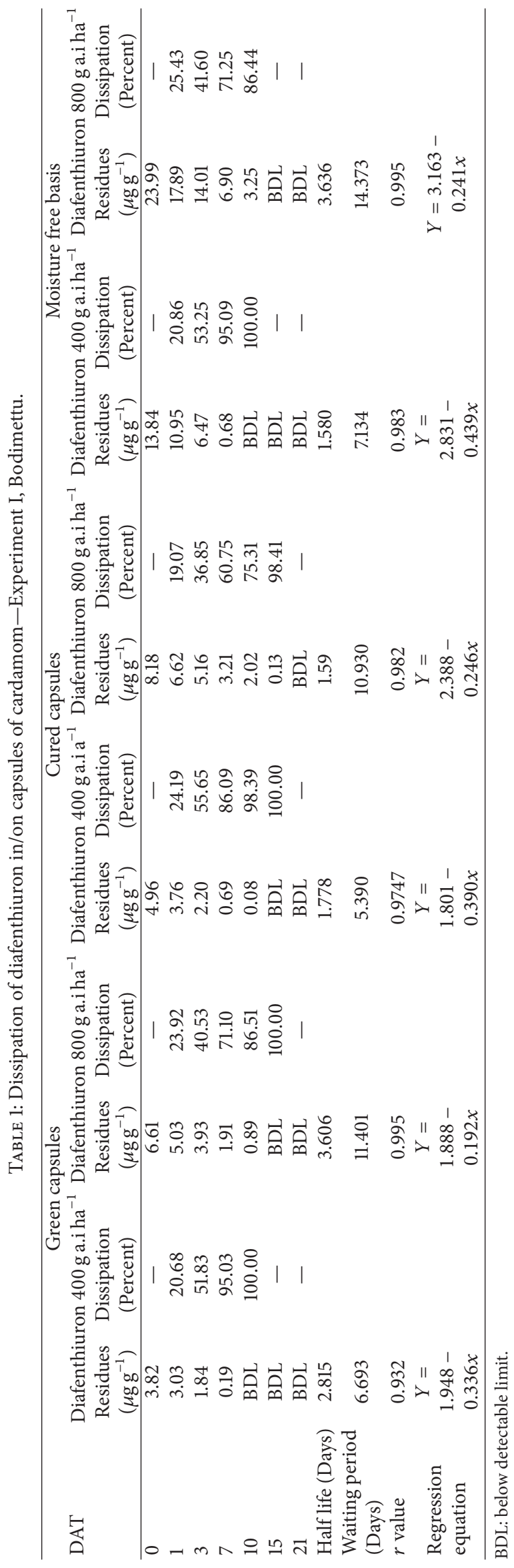




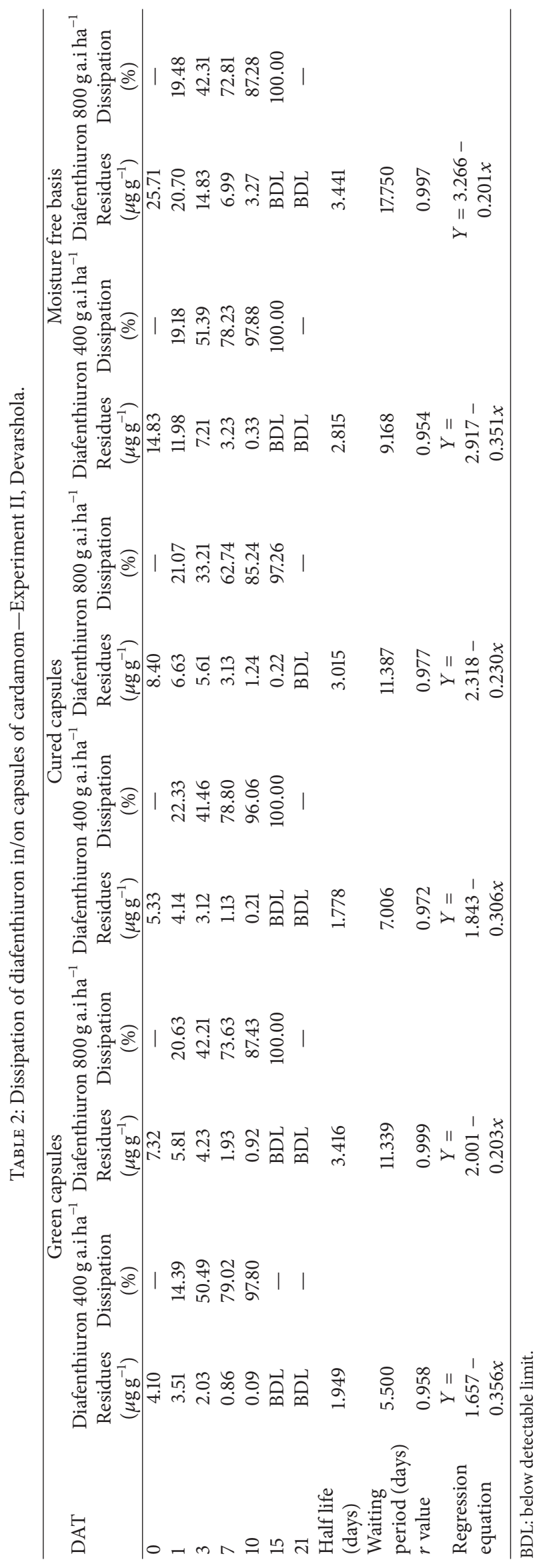




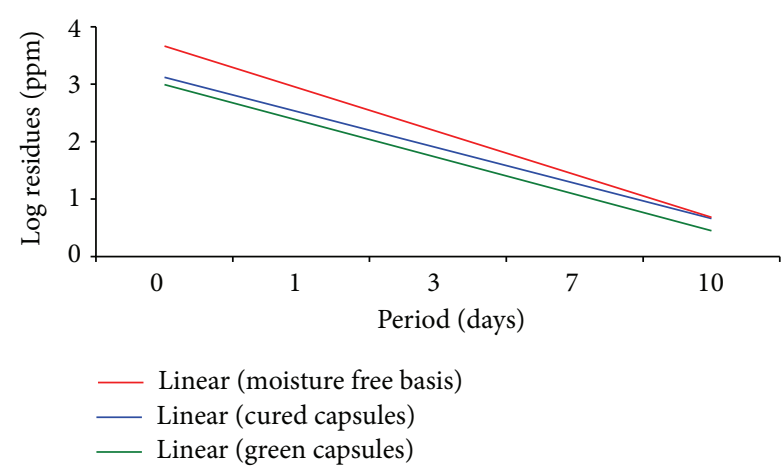

FIGURE 3: Dynamics of diafenthiuron $(0.08 \%)$ residues in cardamom capsules-Experiment I.

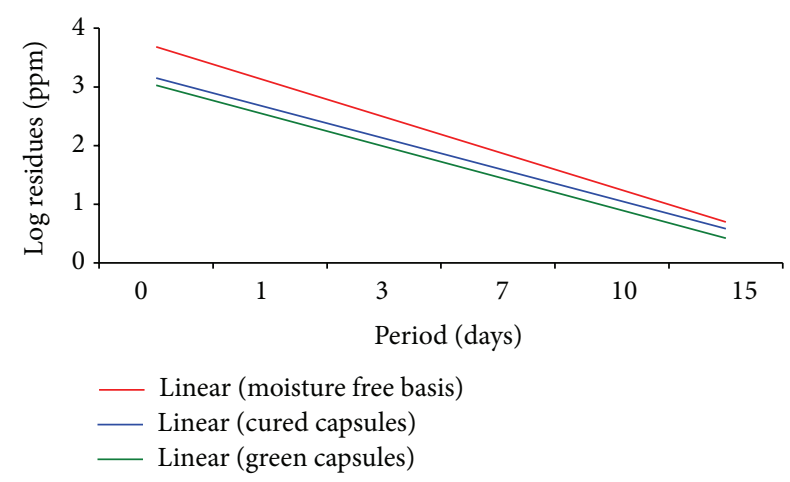

FIGURE 4: Dynamics of diafenthiuron (0.08\%) residues in cardamom capsules-Experiment II.

of residues in curing process (steaming and garbling), the reduction in weight should also be taken into account. The moisture content in green cardamom is about 70 percent. So when the capsules are dried/cured, the residues present in $25 \mathrm{~g}$ of green cardamom sample will get concentrated in about $7 \mathrm{~g}$ of cured capsules. The dissipation of diafenthiuron is slower than the moisture loss during curing. Thus the higher residues of diafenthiuron in cured capsules than green capsules obtained in the present study might be due to the moisture loss and high reduction in weight during curing.

The dissipation pattern of diafenthiuron in cardamom green and cured samples is shown in Figures 3 and 4. The dissipation rate was much faster in the present study which is in line with the reports of Keum et al. [19] stating very high rate of degradation in Chinese cabbage. The waiting period $\left(t_{\mathrm{MRL}}\right)$ for diafenthiuron was arrived at 5.50-6.69 days in green and 7.01-7.13 days in cured capsules at the recommended dose of 0.08 percent. This is lower than the reports made for profenofos 0.05 percent on green (11.76 days) and cured capsules (10.82 days) [27]. The waiting period of lambda cyhalothrin $(80 \mathrm{ppm})$ in cardamom was reported as 8.8 to 10.9 days [28]. The waiting period was reported to be seven days in green capsules of cardamom for diafenthiuron sprayed at $600 \mathrm{~g}$ a.i ha ${ }^{-1}[22]$.

As mentioned earlier, diafenthiuron is not approved by Central Insecticide Board and Registration Committee
(CIB\&RC) for spray in brinjal in view of long waiting period of 10 days but approved for use in cardamom and subjected for fixing of tolerance limits [21]. Picking of cardamom capsules is carried out at an interval of 20-30 days. As harvest being the focal point for enforcement of residue tolerances, the suggested waiting period of seven days is safe enough to contain the cardamom pests with diafenthiuron without the problem of pesticide residues in harvestable produce.

In conclusion, it is clear that diafenthiuron dissipated to a level below detectable by seven days after spraying. Usually cardamom capsules are harvested at an interval of 20-30 days. So spraying of diafenthiuron does not possess any risk of residues in the harvestable produce if sprayed at least seven days before harvesting.

\section{Conflict of Interests}

The authors declare that there is no conflict of interests regarding the publication of this paper.

\section{References}

[1] H. P. Streibert, J. Drabek, and A. Rindisbacher, "Diafenthiuron: a new type of acaricide/insecticide for the control of the sucking pest complex in cotton and other crops," in Proceedings of Brighton Crop Protection Conference, Pests and Diseases, BCPC, Farnham, pp. 25-32, Syrrey, UK, 1988.

[2] I. Ishaaya, S. Kontsedalov, D. Mazirov, and A. R. Horowitz, "Biorational agents in IPM and IRM programs for controlling agricultural pests," Universiteit Gent, vol. 66, pp. 363-374, 2001.

[3] C. Saradha and R. M. Nachiappan, "Evaluation of diafenthiuron 50\% WP (Polo) against whitefly, Bemisia tabaci Genn. (Aleyrodidae: Homoptera) on Brinjal (Solanum mlongena)," Pestology, vol. 27, pp. 12-14, 2003.

[4] J. J. Patel, B. H. Patel, P. D. Bhatt, and A. B. Manghodia, "Bioefficacy of diafenthiuron 50 WP against sucking pests of brinjal (Solanum melangena L.)," in Biodiversity and Insect Pest Management, S. Ignacimuthu and S. Jayaraj, Eds., pp. 57-58, Narosa Publishing House, New Delhi, India, 2006.

[5] M. A. Javed and G. A. Matthews, "Bioresidual and integrated pest management status of a biorational agent and a novel insecticide against whitefly and its key parasitoids," International Journal of Pest Management, vol. 48, no. 1, pp. 13-17, 2002.

[6] J. R. Scarpellani, "Effect of thiamethoxam and diafenthiuron to nymphs of whitefly, Bemisia argentifolli on beans," in Proceedings of the 21th International Conference of Entomology, p. 711, Iguassu Falls, Brazil, August 2000.

[7] A. Noor, Field evaluation of newer insecticides against sucking pests infesting in chillies in Western Rajasthan [Ph.D. thesis], Department of Entomology, Agricultural Research Station, RAU campus, Mandor, Jodhpur, 2001.

[8] M. H. Tatagar, H. D. Mohankumar, R. K. Mesta, and M. Shivaprasad, "Bioefficacy of new molecules Pegasus 50 WP to chilli thrips, Scirtothrips dorsalis (Hood) and mites, Polyphagotarsonemus latus (Banks)," Pestology, vol. 36, no. 2, pp. 19-21, 2012.

[9] UPASI, Seventy Nine Annual Report, Edited by N. Muraleedharan and R. Rajkumar, UPASI Tea Research Found, 2005.

[10] R. Sudhakaran, P. Rajakumari, and A. Mohandhas, "Evaluation of newer insecticides Match 5 EC and Polo 50 SC on the control of insect pests on cotton," Pestology, vol. 19, pp. 14-18, 1995. 
[11] K. R. Kranthi, S. Kranthi et al., "IRM-Revolutionising cotton pest management in India," Resistant Pest Management Newsletter, vol. 14, pp. 33-36, 2004.

[12] I. Ishaaya, Z. Mendelson, and A. R. Horowitz, "Toxicity and growth-suppression exerted by diafenthiuron in the sweetpotato whitefly, Bemisia tabaci," Phytoparasitica, vol. 21, pp. 199204, 1993.

[13] S. Lingappa, K. Basavanagoud, K. A. Kulkarni, S. P. Roopa, and D. N. Kambrekar, "Threat to vegetable production by diamondback moth and its management strategies," in Disease Management in Fruits and Vegetables, pp. 357-396, Springer, Amsterdam, The Netherlands, 2004.

[14] J. Stanley, S. Chandrasekaran, G. Preetha, and S. Kuttalam, "Toxicity of diafenthiuron to honey bees in laboratory, semifield and field conditions," Pest Management Science, vol. 66, no. 5, pp. 505-510, 2010.

[15] J. Drabek, M. Boger, J. Ehrenfreund et al., "New thioureas as insecticides," in Recent Advances in the Chemistry of Insect Control II, C. Crobie, Ed., vol. 79 of Special Publication, pp. 170183, Royal Society of Chemistry, Cambridge, UK, 1992.

[16] H. A. Kadir and C. O. Knowles, "Toxicological studies of the thiourea diafenthiuron in diamondback moths and two spotted spider mites and bulb mites," Journal of Economic Entomology, vol. 84, pp. 780-784, 1991.

[17] IUPAC, Detection and Significance of Active Metabolites of Agrochemicals and Related Xenobiotics in Animals, vol. 67 of Edited by R.M. Hollingworth, N. Kurihara, J. Miyamoto, S. Otto and G.D. Paulson, International Union of Pure and Applied Chemistry, 1995.

[18] H. Kayser and P. Eilinger, "Metabolism of diafenthiuron by microsomal oxidation: procide activation and inactivation as mechanisms contributing to selectivity," Pest Management Science, vol. 57, pp. 975-980, 2001.

[19] Y.-S. Keum, J.-H. Kim, Y.-W. Kim, K. Kim, and Q. X. Li, "Photodegradation of diafenthiuron in water," Pest Management Science, vol. 58, no. 5, pp. 496-502, 2002.

[20] Y. S. Keum, K. H. Liu, J. S. Seo et al., "Dissipation of foliar residues of diafenthiuron and its metabolites," Bulletin of Environmental Contamination and Toxicology, vol. 68, no. 6, pp. 845-851, 2002.

[21] CIB\&RC, "Central Insecticide Board and Registration Committee," 2006, http://www.cibrc.nic.in/267rc.doc.

[22] D. Rajabaskar and A. Regupathy, "Persistence of diafenthiuron in cardamom," Pesticide Research Journal, vol. 20, pp. 247-249, 2008.

[23] S. Navickiene, A. Aquino, and D. S. S. Bezerra, "A matrix solidphase dispersion method for the extraction of seven pesticides from mango and papaya," Journal of Chromatographic Science, vol. 48, no. 9, pp. 750-754, 2010.

[24] APVMA, "The standard MRL in food and animal feed stuff. May 2007. Maximum residue levels of Agricultural and Veterinary chemicals and associated substances in food commodities," 2007, http://www.apvma.gov.au/residues/.

[25] Table of MRLs for Agricultural Chemicals, "The Japan Food Chemical Research Foundation,” 2010, http://www.ffcr.or.jp/.

[26] S. Valarmathi and A. Regupathy, "Evaluation of two ecofriendly formulations of quinalphos aqua flow (AF) and colloidal suspension (CS) on cardamom residues," in 14th International Plant Protection Congress (IPPC '99), Jerusalem, Israel, July 1999.

[27] D. Rajabaskar, Studies on the evaluation of IPM modules against Conogethes punctiferalis Guenee and Sciothrips cardamomi
Ramk. on cardamom [Ph.D. thesis], Tamil Nadu Agricultural University, Coimbatore, India, 2003.

[28] A. Regupathy, R. S. S. Kumar, D. Rajabaskar, and K. Chozhan, "Determination of residues of profenophos in cardamom," in Proceedings of National Seminar on Resource Management in Plant Protection during Twenty First Century, Hyderabad, India, 2002. 

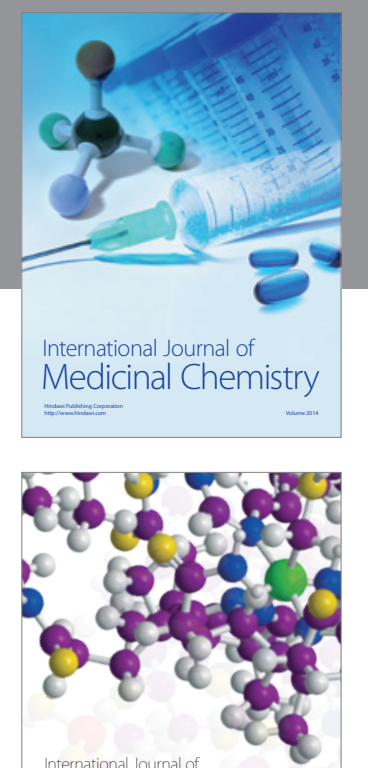

\section{Carbohydrate} Chemistry

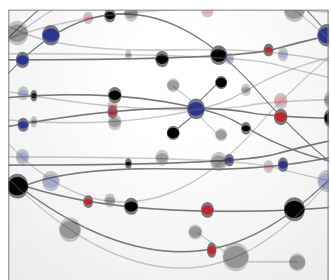

The Scientific World Journal
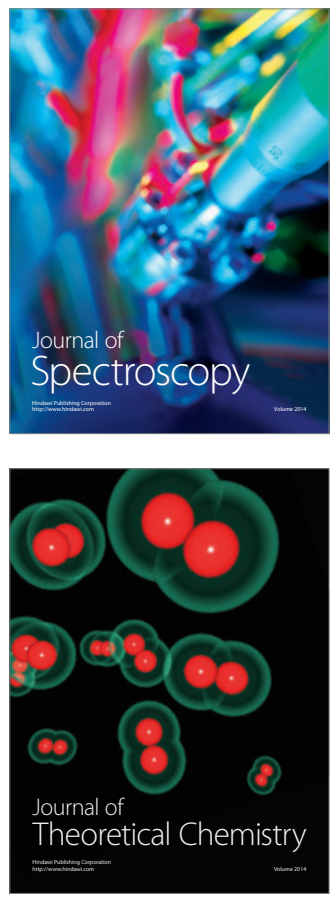
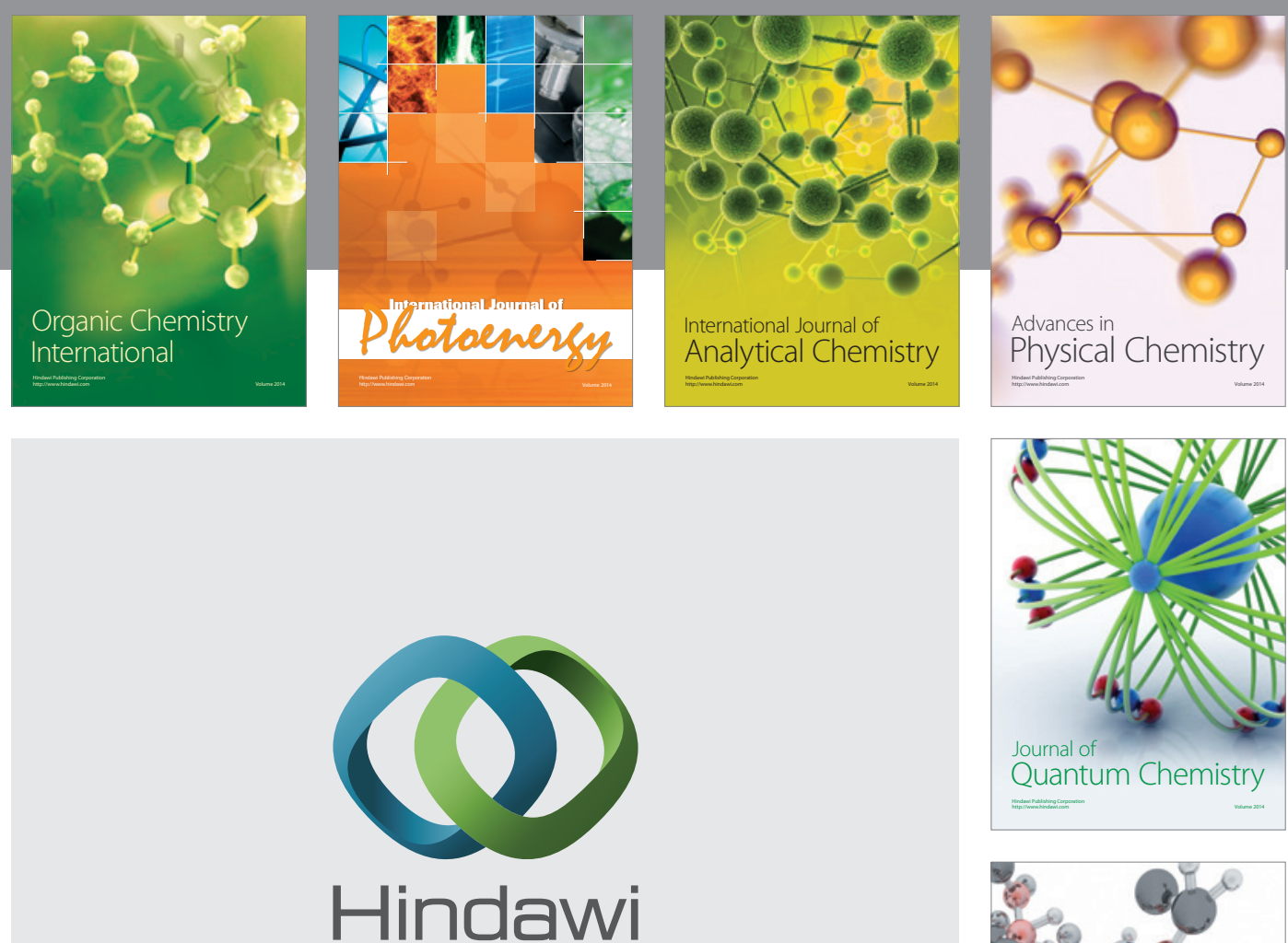

Submit your manuscripts at

http://www.hindawi.com

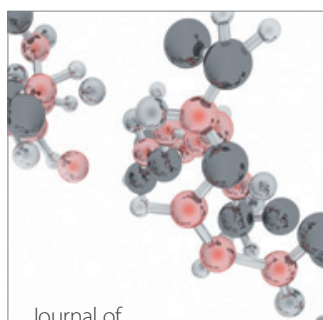

Analytical Methods

in Chemistry

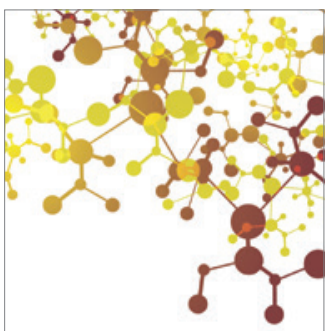

Journal of

Applied Chemistry

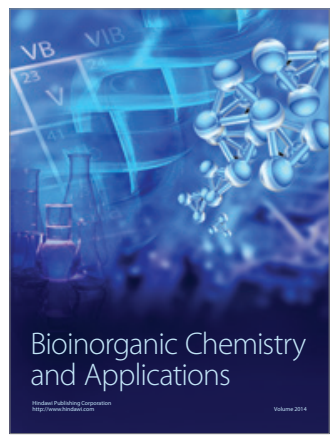

Inorganic Chemistry
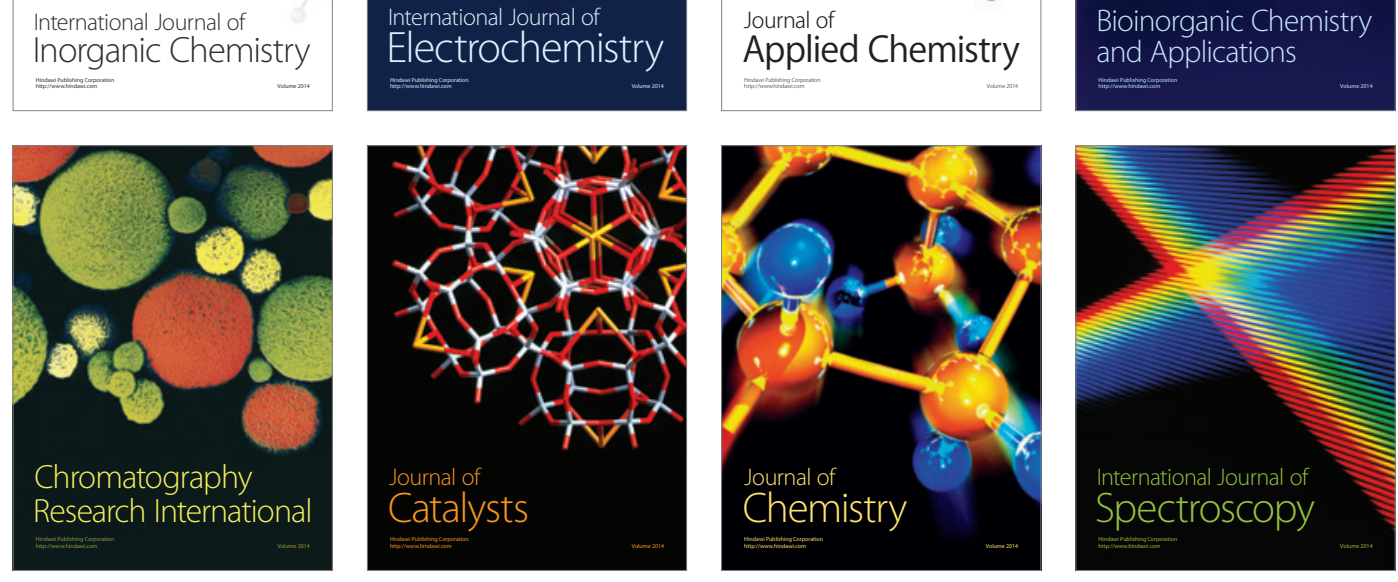